\title{
NATURAL POLYMERS IN THE DEVELOPMENT OF FLOATING DRUG DELIVERY SYSTEMS: A REVIEW.
}

\author{
Kumar Ganesh, Dhyani Archana, Kothiyal Preeti \\ Sri Guru Ram Rai Institute of Technology and Sciences \\ Patel Nagar, Dehradun, India
}

\begin{abstract}
:
The purpose of writing this review on floating drug delivery systems (FDDS) was to compile the recent literature with special focus on the principal mechanism of floatation to achieve gastric retention. This can be achieved by use of various polymeric substances including natural polymers. These polymers are inexpensive, safe and available in a variety of structures with versatile characteristics. Large number of derivatizable groups, wide range of molecular weights, varying chemical composition gel forming nature of these polymers also provide an exciting opportunities in the fascinating arena of applied polymer science and drug delivery technology. All these characteristics make them suitable candidate for design and fabrication of novel gastroretentive drug delivery systems. Various natural polymers have been investigated worldwide by scientific community for their potential as floating drug delivery systems. The present article highlights various recent efforts and advanced approaches exploiting several natural polymers in this technology.
\end{abstract}

Keywords : Floating Drug Delivery Systems, Natural Polymers, Site-Specific, Bioavailability.

\section{Introduction}

Gastric emptying of dosage forms is an extremely variable process and ability to prolong and control the emptying time is a valuable asset for dosage forms, which reside in the stomach for a longer period of time than conventional dosage forms. Several difficulties are faced in designing controlled release systems for better absorption and enhanced bioavailability. ${ }^{[1,2,3]}$ One of such difficulties is the inability to confine the dosage form in the desired area of the gastrointestinal tract. Drug absorption from the gastrointestinal tract is a complex procedure and is subject to many variables. It is widely acknowledged that the extent of gastrointestinal tract drug absorption is related to contact time with the small intestinal mucosa. Thus, small intestinal transit time is an important parameter for drugs that are incompletely absorbed. ${ }^{[4]}$

${ }^{*}$ Correspondence to author:

Archana Dhyani

Division of Pharmaceutical Sciences, Patel Nagar, Dehradun, Uttarakhand-248001

India.

e-mail address: archana.dhyani89@gmail.com 
Gastroretentive systems can remain in the gastric region for several hours and hence significantly prolong the gastric residence time of drugs. Prolonged gastric retention improves bioavailability, reduces drug waste, and improves solubility for drugs that are less soluble in a high $\mathrm{pH}$ environment. It has applications also for local drug delivery to the stomach and proximal small intestines. Gastro retention helps to provide better availability of new products with new therapeutic possibilities and substantial benefits for patients. ${ }^{[5]}$

\section{Approaches to gastric retention}

The controlled gastric retention of solid dosage forms may be achieved by the mechanisms of mucoadhesion ,flotation, sedimentation, expansion, modified shape systems, or by the simultaneous administration of pharmacological agents that delay gastric emptying. ${ }^{[6-9]}$

\section{Polymers in floating drug delivery systems}

For more than two decades, considerable use of polymeric materials to deliver bioactive agents has attracted attention of various investigators throughout the scientific community. Polymer chemists, chemical engineers along with pharmaceutical scientists are highly engaged in bringing out the design and development of various controlled drug delivery systems. ${ }^{[10]}$ Polymers are generally employed in floating drug delivery systems so as to target the delivery of drug to a specific region in the gastrointestinal tract i.e. stomach. ${ }^{[11]}$ Both synthetic and natural polymers have been studied extensively in the design of drugdelivery systems. In spite of the advent of many synthetic polymers, use of natural polymeric materials has gained lot of importance during the last two decades in drug delivery arena. Incorporation of natural polymers in various drug delivery systems looks to be an active avenue of research and development due to obvious reasons of compatibility, inexpensive and ready availability. ${ }^{[10]}$ These polymers, particularly with pronounced swelling properties have been frequently employed in the formulation of different gastroretentive products. ${ }^{[12]}$

Drug delivery systems targeted to stomach which are based on the utilization of various natural polymer offer superiority over other systems. Moreover, these polymers are safe, nontoxic, capable of chemical modification and gel forming nature. Natural polymers which have been explored for their promising potential in stomach-specific drug delivery include chitosan, pectin, xanthan gum, guar gum, gellan gum,karaya gum, psyllium husk, starch, alginates etc. ${ }^{[13]} \mathrm{A}$ list of natural polymers along with structural features is also illustrated in the following Table 1.

Table 1. Important structural features and sources of natural polymer pursued for floating drug delivery systems

\begin{tabular}{|c|c|c|}
\hline Natural polymer & Basic chain & Source \\
\hline Chitosan & $\begin{array}{c}\text { Deacetylated P-1, 4-N-acetyl-1- } \\
\text { D-glucosamine }\end{array}$ & Shell of marine invertebrates \\
\hline Pectin & $\begin{array}{l}\lambda \text {-(1,4)- linked D-galacturonic } \\
\text { acid }\end{array}$ & $\begin{array}{l}\text { Citrus peel, apple pomace, sugar } \\
\text { beet pulp etc. }\end{array}$ \\
\hline Xanthan gum & $\lambda$-(1,4)-linked D-glucose & Fermentation of glucose by \\
\hline
\end{tabular}




\begin{tabular}{|c|c|c|}
\hline Natural polymer & Basic chain & Source \\
\hline Guar gum & $\lambda$-D-mannopyranose & $\begin{array}{l}\text { Xanthomonas campestris } \\
\text { Endosperm of the seeds of } \\
\text { Cyamopsis tetragonolobus }\end{array}$ \\
\hline Alginates & $\begin{array}{l}\text { 1-4' linked-B-D-mannuronic } \\
\text { acid and } \beta \text {-L-glucuronic acid }\end{array}$ & $\begin{array}{l}\text { Laminaria hyperborea, Ascophyllum } \\
\text { nodosum, Macrocystis pyrifera etc. }\end{array}$ \\
\hline Gellan gum & $\begin{array}{l}\text { D-glucose, D-glucuronic acid } \\
\text { and rhamnose in B-1, } 4 \text { linkage }\end{array}$ & Pseudomonas elodea \\
\hline Starch & $\begin{array}{l}\alpha-(1,4) \text {-linked D-glucose } \\
\text { and } \alpha-(1,6) \text {-linked D-glucose }\end{array}$ & Storage polysaccharide in plants \\
\hline Karaya Gum & $\alpha$-D-galacturonic, $\alpha$-L-rhamnose & $\begin{array}{l}\text { Exudate by trees of the genus } \\
\text { Sterculia }\end{array}$ \\
\hline Honey locust gum & $\begin{array}{l}\beta \text {-D-mannan backbone linked } \\
\alpha \text {-D-galactose side groups }\end{array}$ & Gleditsia triacanthos \\
\hline Tamarind Gum & - & Tamarindus indica \\
\hline Aloe Mucilage & mannan (or acemannan) & Aloe barbadensis Miller \\
\hline Psyllium Husk & cyclopentano pyridine & Plantago ovate \\
\hline Fenugreek & & Trigonella Foenum-graceum \\
\hline
\end{tabular}

\section{Chitosan}

Chitosan is a natural and versatile polymer obtained by alkaline deacetylation of chitin. It has favourable biological properties such as non toxicity, biocompatiblity, and biodegradability. These properties make chitosan a good candidate for the development of various conventional and novel gastrointestinal dosage forms. Being a bioadhesive polymer and having antibacterial activity, this polymer is a excellent agent for site specific drug delivery. Chitosan molecule is a copolymer of $\mathrm{N}$-acetyl-D-glucosamine and D-glucosamine (Chemical structure is shown in Fig. 1). ${ }^{[12]}$ 
Chitosan has the characteristic of forming gels in addition to possessing viscosity-related properties, complete biodegradability, and even anti-tumor influence ${ }^{[16]}$. Its bacteriostatic and fungistatic properties are particularly useful for wound treatment. Furthermore,chitosan possesses bioadhesive properties which make it of interest in bioadhesive sustained release formulation required ${ }^{[16,17]}$

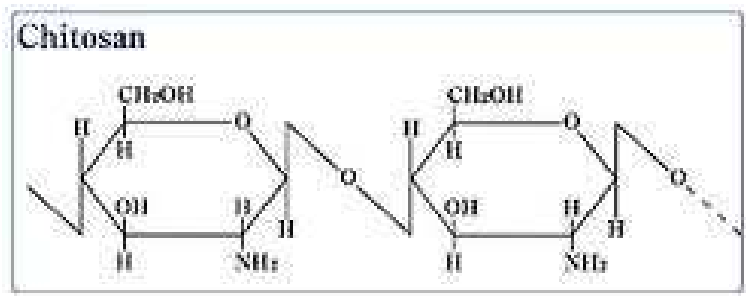

Figure 1: Structure of Chitosan

Chitosan is a high molecular weight polycationic weak base with pKa value of the Dglucosamine residue of about 6.2-7.0 and therefore, is insoluble at neutral and alkaline $\mathrm{pH}$ values. Chitosan granules with internal cavities can be prepared by deacidification. On addition to acidic ( $\mathrm{pH}$ 1.2) and neutral (deionized distilled water) media, these granules immediately become buoyant in nature and provide a controlled release of the drug. Laminated preparations prepared by coating of chitosan granule's layer with chitosan membranes also showed buoyancy and controlled release of the drug. By increasing the chitosan membrane's thickness, the release rate of the drug decreased. ${ }^{[14]}$ Both chitosan granules and chitosan-laminated preparations could be helpful in developing drug delivery systems that will reduce the effect of gastrointestinal transit time ${ }^{[15]}$

\section{Pectin}

Pectins are non-starch, linear polysaccharides present in the walls that surround growing and dividing plant cells. They are predominantly linear polymers of primarily $\alpha-(1,4)$-linked $D$ galacturonic acid residues interrupted by 1,2-linked L-rhamnose residues having an average molecular weight of about 50,000 to about 180,000 (Fig. $2^{\text {[18] }}$

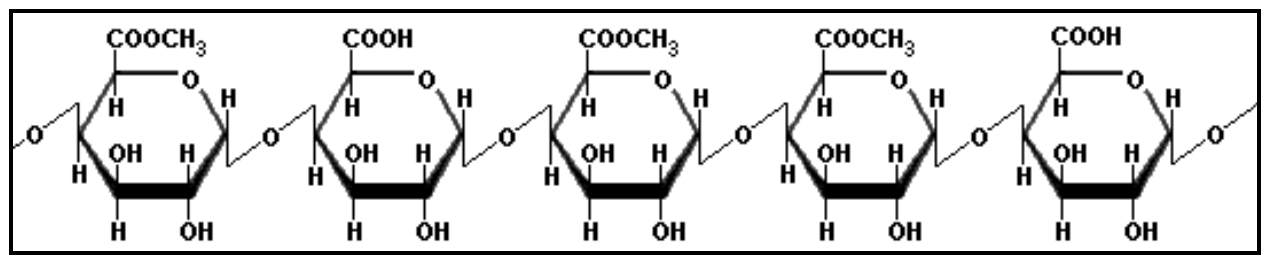

Figure 2: Structure of Pectin

It is soluble in water, insoluble in ethanol (95\%) and other organic solvents. The main sources of commercial pectin are citrus peel (lemon, lime and grapefruit), apple pomace and sugar beet pulps. Pectins from different sources are widely used as gelling agents, thickeners, texturisers, emulsifiers and stabilisers in food, pharmaceutical, and many other industries. Pectin gel beads have been shown to be an effective medium for controlling the release of a drug within the gastrointestinal tract.Chemical modifications of pectin can lead to new products with significant 
physicochemical and biological properties Pectin is classified according to its degree of esterification (DE). Pectin with at least $50 \%$ DE or greater is high-methoxypectin, and the one with DE below $50 \%$ is low-methoxypectin. These two types of pectin possess different properties; for example, low-methoxy pectin requires calcium to gel, and high ester pectins are capable of forming gels in aqueous systems with high contents of soluble solids and low $\mathrm{pH}$ values. $^{[18]}$

\section{Xanthan Gum}

Xanthan gum is a high molecular weight extracellular polysaccharide produced by pure culture aerobic fermentation of carbohydrate with Xanthomonas campestris bacteria.Xanthan is a long chained polysaccharide with large number of trisaccharide side chains. The main chain consists of $\alpha$ - $(1,4)$-linked D-glucose units. The side chains are composed of two mannose units and one glucuronic acid unit (Fig. 3).This gum develops a weak structure in water, which creates high viscosity solutions at low concentration. Viscosity remains fairly constant from $0^{\circ} \mathrm{C}$ to $100^{\circ} \mathrm{C}$.(Fig. 3)

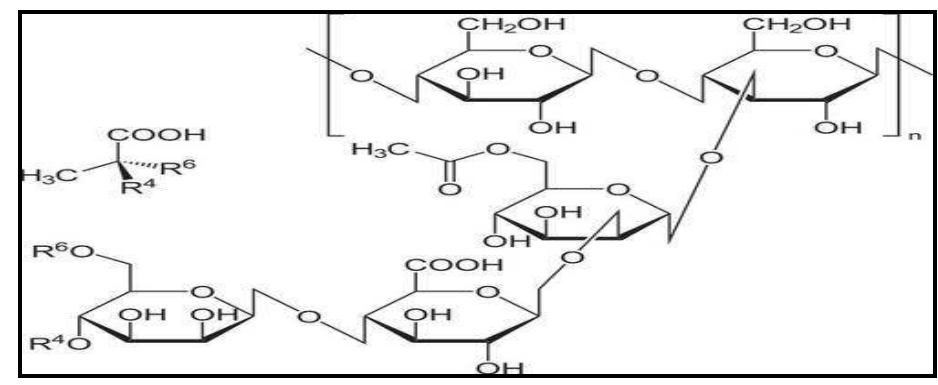

Figure 3: Structure of Xanthan gum

Anionic character of this polymer is due to the presence of both glucuronic acid and pyruvic acid groups in the side chain. This gum is a cream coloured powder that is soluble in hot or cold water with high viscosity even at low concentrations.Gum also has an excellent solubility and stability under acidic and alkaline conditions and in the presence of salts and resists common enzymes. ${ }^{[24]}$

\section{Guar Gum}

Guar gum is naturaly occurring galactomannan polysaccharide, made up of linear chain of $\beta$-Dmannopyranose joined by B-(1-4) linkage with $\alpha$ - D-galactopyranosyl units attached by 1,6-links in the ratio of 1:2 (Fig.4).It is obtained from the ground endosperms of the leguminous plant Cyamopsis tetragonolobus (L.)Taub., a species cultivated in India as a fodder crop.

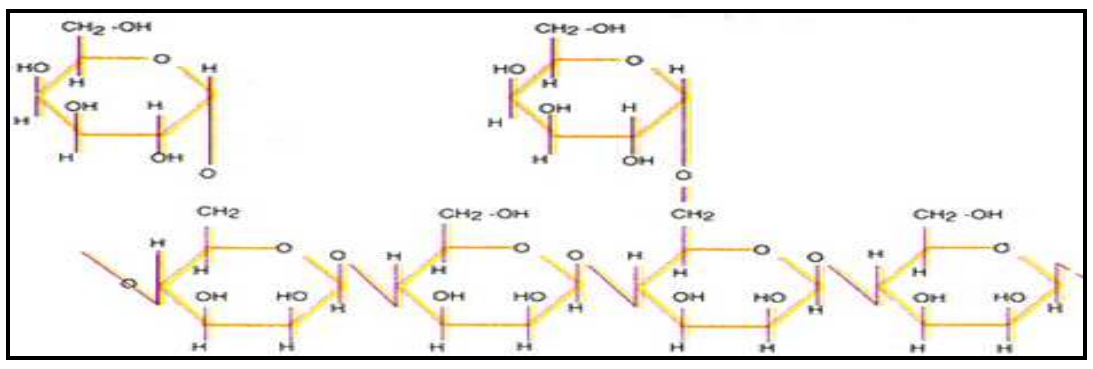

Figure 4: Structutre of Guargum 
Guar gum hydrates and swells in cold water forming viscous colloidal dispersions or sols. This gelling property retard the drug release and make it a flexible carrier for extended release

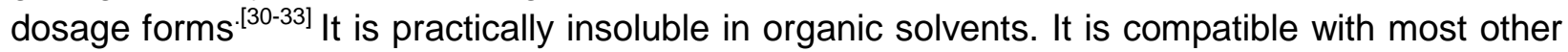
plant hydrocolloids such as tragacanth and incompatible with acetone, ethanol (95\%), tannins, strong acids and alkalis. This polymeric material has been studied extensively as an inexpensive and flexible carrier for different floating dosage forms.

\section{Gellan Gum}

Gellan gum is an anionic, high molecular weight, deacetylated extracellular linear polysaccharide comprising glucuronic acid, rhamnose and glucose (Fig. 5). It is produced as a fermentation product by a pure culture of Pseudomonas elodea ${ }^{[19]}$

Gellan gum, also commercially known as Phytagel or Gelrite. It is capable of gelation in the presence of mono- and divalent ions. It is available in two forms (high or low acyl content). This gum has an outstanding flavor release, high gel strength, an excellent stability, process flexibility, high clarity, good film former and thermally reversible gel characteristics.

It is also used as a texturizing and suspension hydrocolloid agent. ${ }^{[20]}$ This gum has been considered as a potential carrier for different floating dosage forms by various investigators.

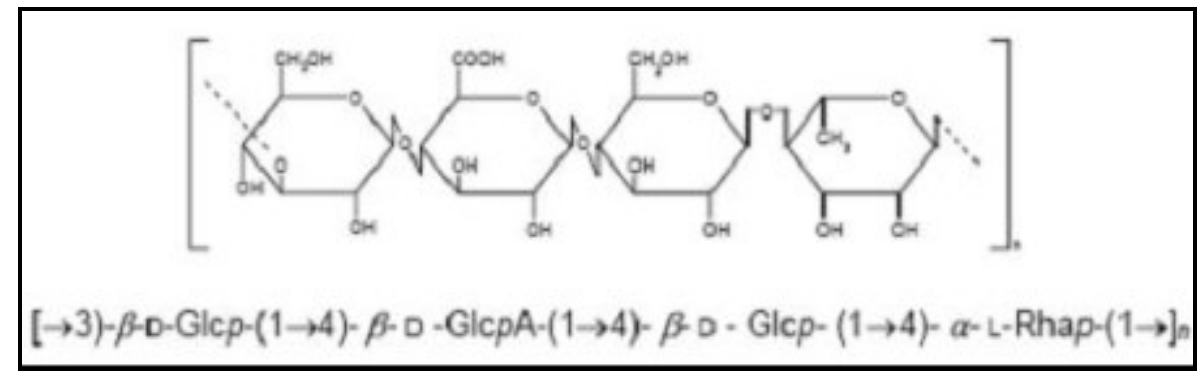

Figure 5:Structure of Gellan gum

\section{Karaya Gum}

Karaya gum is a vegetable gum produced as an exudate by trees of the genus Sterculia. Chemically, gum karaya is an acid polysaccharide composed of the sugars galactose, rhamnose, and galacturonic acid. The gum is glycanorhamnogalacturonan type having a central backbone with a basic unit consisting of alternating a-D-galacturonic acid linked through the C-4 position and $\alpha$-L-rhamnose linked through the $\mathrm{C}-2$ position. The chain is substituted on the galacturonic acid hydroxyl groups in C-2 or C-3 and on some of the rhamnose hydroxyl groups in $\mathrm{C}-4$ by D-galactose and D-glucuronic acid. ${ }^{[21]}$

Traditionally, India is the largest producer and exporter of Karaya gum. This gum is very less expensive and currently used in a variety of products, including cosmetics, hair sprays, and lotions, to provide bulk. Gum is least soluble of commercial plant exudates, but it absorbs water rapidly and swells to form viscous colloidal solutions even at low concentrations (1\%). ${ }^{[21]}$ Swelling behavior of karaya gum is dependent upon the presence of acetyl groups in its structure. 


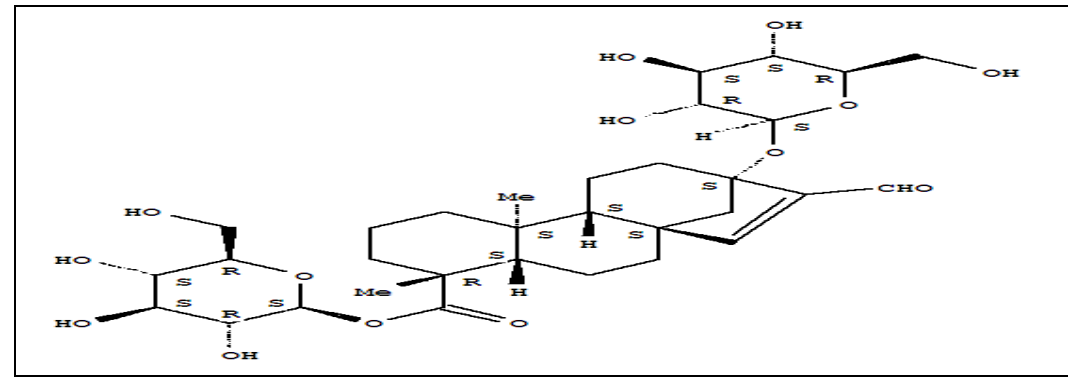

Figure 6:Structure of Karaya gum

In an independent investigation Sterculia foetida gum as a hydrophilic matrix polymer for controlled release preparation was evaluated. Different formulation aspects considered were: gum concentration (10-40\%), particle size $(75-420 \mu \mathrm{m})$ and type of fillers. Tablets prepared with Sterculia foetida gum were compared with tablets prepared with Hydroxy methyl cellulose $\mathrm{K} 15 \mathrm{M}$. The release rate profiles were evaluated through different kinetic equations: zero-order, first-order, Higuchi, Hixon-Crowell and Korsemeyer and Peppas models. Suitable matrix release profile was obtained at $40 \%$ gum concentration. Higher sustained release profiles were obtained for Sterculia foetida gum particles in size range of 76- $125 \mu \mathrm{m}$. The in vitro release profiles indicated that tablets prepared from Sterculia foetida gum had higher retarding capacity than tablets prepared with Hydroxy methyl cellulose K15M prepared tablets. ${ }^{[4]}$

\section{Tamarind Gum:}

Tamarind xyloglucan is obtained from the endosperm of the seed of the tamarind tree, Tamarindus indica, a member of the evergreen family. Tamarind Gum, also known as Tamarind Kernel Powder (TKP) is extracted from the seeds. The seeds are processed in to gum by seed selection, seed coat removal,separation, hammer milling, grinding and sieving. Tamarind gum is a polysaccharide composed of glucosyl : xylosyl : galactosyl in the ratio of 3:2:1. Xyloglucan is a major structural polysaccharide in the primary cell walls of higher plants. Tamarind xyloglucan has a $(1,4)-$ !-D-glucan backbone that is partially substituted at the 0-6 position of its glucopyranosyl residues with $\mathrm{D}$-xylopyranose.Some of the xylose residues are $\beta$-Dgalactosylated at O-2 (fig 7) ${ }^{[22]}$

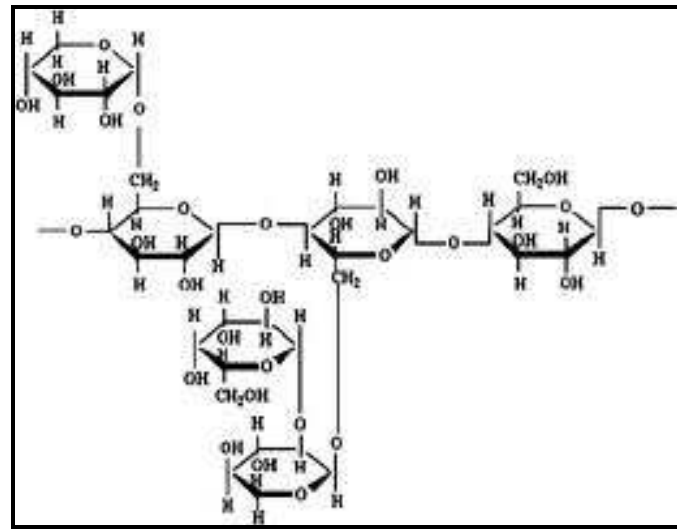

Figure 7: Structure of Tamarind gum 


\section{Honey locust gum:}

It is known botanically as Gleditsia triacanthos, and belongs to the order Leguminosea(suborder Mimoseae). The gum is obtained from the seeds of the plant. The seed contains proteins, fats, carbohydrates and fibers. ${ }^{[23]}$

The gum contains $88 \%$ D-galacto-Dmannoglycan, $4 \%$ pentan, $6 \%$ of proteins, $1 \%$ cellulose and $1 \%$ ash. Plant seed galactomannan, composed of a 1-4 linked $\beta$-D-mannan backbone with 1- 6linked $\alpha-D$-galactose side groups. This neutral polymer is only slightly soluble in cold water; it requires heat to achieve full hydration, solubilization and maximum viscosity ${ }^{[24]}$

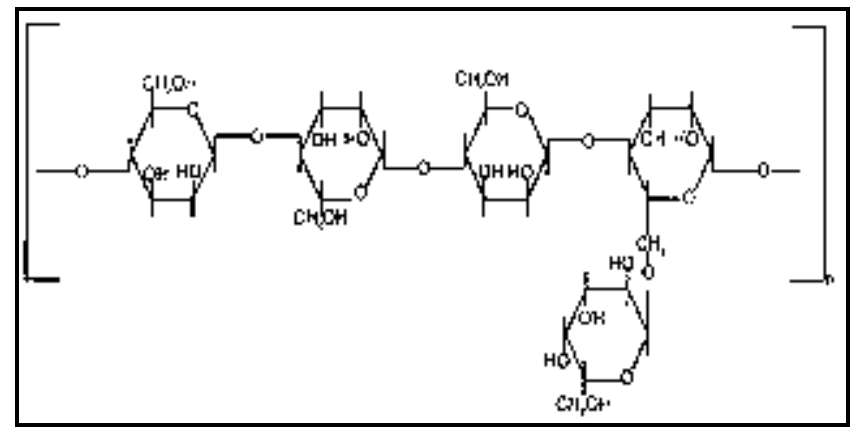

Figure 8:Structure of Honey locust gum

\section{Aloe Mucilage:}

Aloe mucilage is obtained from the leaves of Aloe barbadensis Miller.The aloe parenchyma tissue or pulp has been shown to contain proteins, lipids, amino acids, vitamins, enzymes, inorganic compounds and small organic compounds in addition to the different carbohydrates. Many investigators have identified partially acetylated mannan (or acemannan) as the primary polysaccharide of the gel, while others found pectic substance as the primary polysaccharide.[25]

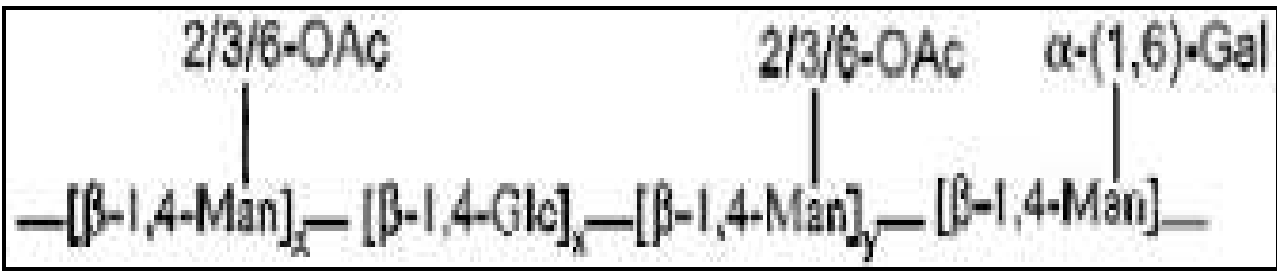

Figure 9:Chemical structure of acemannan

Other polysaccharides such as arabinan ,arabinorhamnogalactan, galactan, galactogalacturan, glucogalactomannan, galactoglucoarabinomannan and glucuronic acid containing polysaccharides have been isolated from the Aloe vera inner leaf gel part. ${ }^{[26]}$

$A$. vera has been used for many centuries for its curative and therapeutic properties. In the pharmaceutical industry, it has been used for the manufacture of topical products such as ointments and gel preparations, as well as in the production of tablets and capsules [27] Important pharmaceutical properties that have been recently discovered for both the $A$. vera gel and whole leaf extract include the ability to improve the bioavailability of co-administered vitamins in human subjects ${ }^{[28]}$ 


\section{Psyllium Husk}

Psyllium husk obtained from dried seed coats of Plantago ovate is swellable, biocompatible, inexpensive, inert, environment friendly and easily available polymeric substance.The seed contains $5-10 \%$ lipids with unsaturated fatty acids, sterols, proteins (15-18\%), traces of cyclopentano pyridine-type alkaloids, aucubin and carbohydrates-planteose, a trisaccharide, and $10-12 \%$ mucilage of the heteroxylan type.Psyllium husk has also release retardant properties. ${ }^{[29]}$ Above discussed characteristics reveal that psyllium husk is most likely to serve as a viable means for gastroretentive drug delivery system. Various researchers have also focused on the use of this polymer for prolonged retention of dosage form in the stomach.

\section{Starch}

Starch constitutes the principle form of carbohydrate reserve in the green plants and is found especially in seeds and subground organs. It occurs in the form of granules (starch grains), the shape and size of which are characteristics of the species. ${ }^{[30]}$ It is comprised of two polymers, namely amylose (a non-branching helical polymer consisting of $\alpha-1,4$ linked $D$ glucose monomers) and amylopectin (a highly branched polymer consisting of both $\alpha-1,4$ and $\alpha-1,6$ linked D-glucose monomers) (Fig. 10).

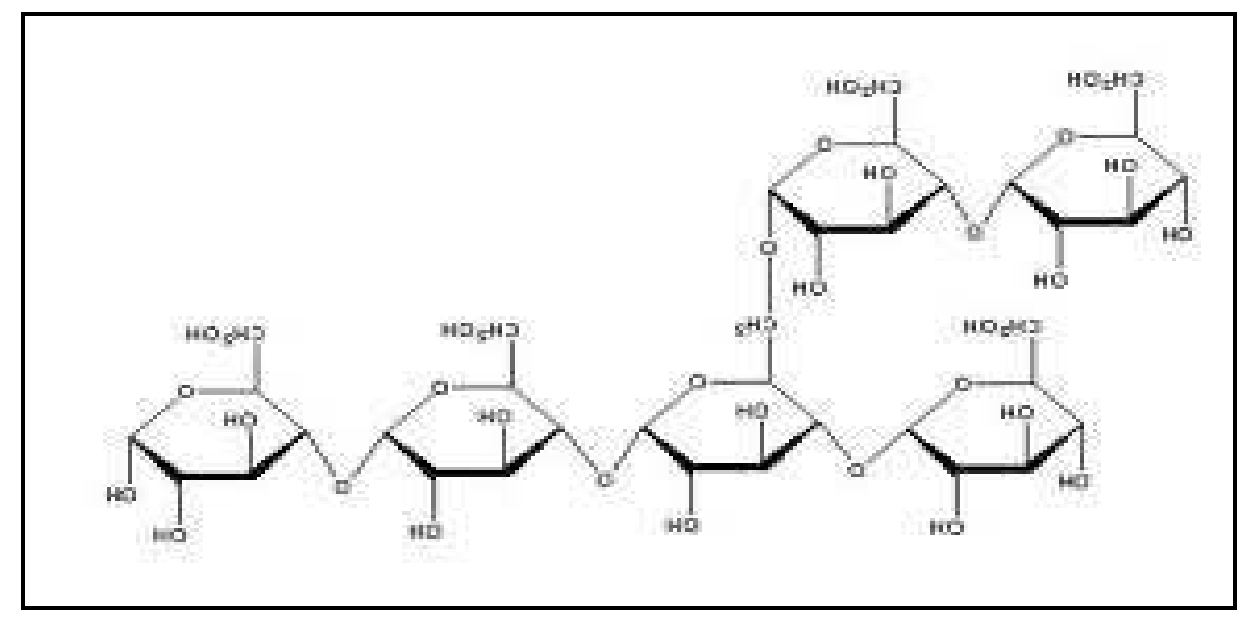

Figure 10: Structure of Starch

Amylose is crystalline in nature and can have a number average molecular weights as high as $5,00,000$. It is soluble in boiling water but amylopectin is insoluble in boiling water. Both fractions are readily hydrolyzed at the acetal link by enzymes. Number of starches has been studied for various pharmaceutical applications. These include maize (Zea mays), rice (Oryza

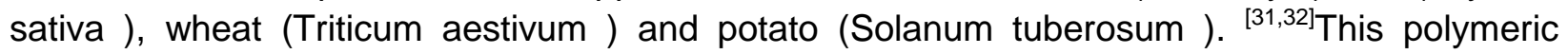
material has enormous applications in the fabrication of different floating dosage forms .

\section{Alginates}

Alginates are hydrophilic, non toxic, biodegradable, linear polymer consisting of 1-4' linked-B-Dmannuronic acid and $\beta$-L-glucuronic acid residues arranged as blocks of either type of unit or as a random sharing of each type ${ }^{[33,34]}$ (fig. 11) 


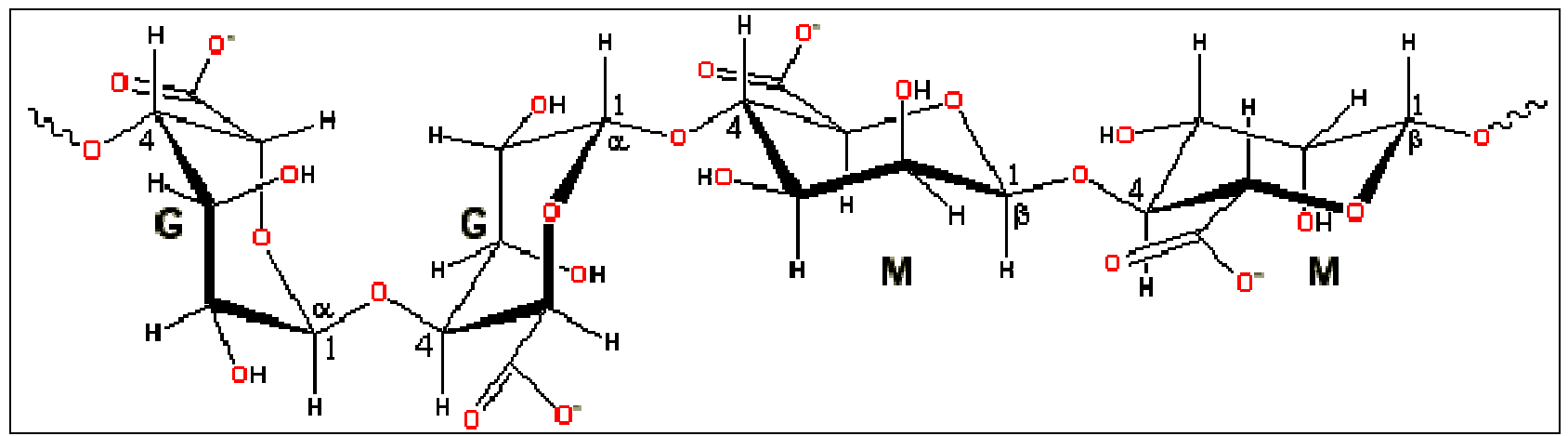

Figure 11:Structure of Alginates

These are unbranched polysaccharides found in brown seaweed and marine algae such as Laminaria hyperborea, Ascophyllum nodosum and Macrocystis pyrifera ${ }^{[11]}$. Many different alginate salts and derivatives are also commercially available including sodium alginate, ammonium alginate, calcium alginate, magnesium alginate, potassium alginate etc. Out of these, sodium alginate is most commonly and widely used in floating drug delivery systems.

It is practically insoluble in ethanol (95\%), ether, chloroform and slowly soluble in water, forming viscous colloidal solution. ${ }^{[35]}$ Favorable properties of alginates have attracted a lot of concern towards the development of different floating dosage forms.

\section{Fenugreek:}

Trigonella Foenum-graceum, commonly known as Fenugreek, is an herbaceous plant of the leguminous family.Fenugreek seeds contain a high percentage of mucilage (a natural gummy substance present in the coatings of many seeds). Although it does not dissolve in water, mucilage forms a viscous tacky mass when exposed to fluids. Like other mucilage- containing substances, fenugreek seeds swell up and become slick when they are exposed to fluids .[36] An extraction procedure is also reported to isolate the mucilage from the husk. The powdered seeds are extracted with hexane then boiled in ethanol. The treated powder is then soaked in water and mechanically stirred and filtered. Filtrate is then centrifuged, concentrated in vacuum and mixed with $96 \%$ ethanol. This is then stored in refrigerator for 4 hrs to precipitate the mucilage ${ }^{[37]}$. Fenugreek mucilage at a concentration of about $66 \% \mathrm{w} / \mathrm{w}$ was found to be a better release retardant.

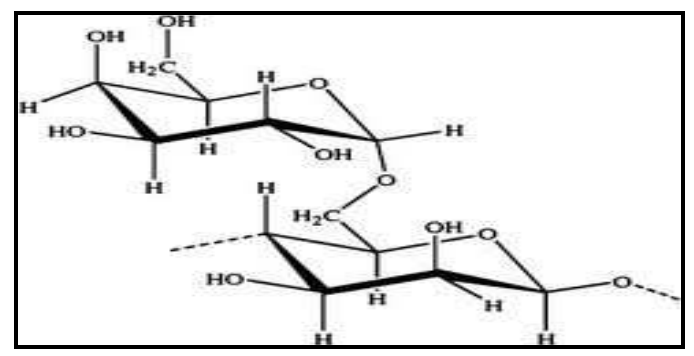

Figure 12:Structure of Fenugreek 


\section{Carrageenans:}

Carrageenans is the generic name for a family of high molecular weight sulphated polysaccharides obtained from certain species of red seaweeds belonging to the class Rhodophyceae, especially Chondrus crispus, Euchema spp, Gigartina stellata and Iridaea spp [40]. There are three basic types of carrageenan : kappa (K), iota (I) and lambda $(\lambda)$. The $\lambda$-type carrageenan results in viscous solutions but is non-gelling, while the $\mathrm{k}$-type carrageenan forms a brittle gel. The ı-type carrageenan produces elastic gels ${ }^{[41]}$.

Compaction ability of two K-carrageenans (Gelcarin® GP-812 NF and GP911 NF) and one Icarrageenan (Gelcarin $\AA$ GP-379 NF) was studied and concluded that these are suitable excipients for the manufacturing of controlled-release tablets ${ }^{[42]}$

\section{Conclusion and prospects}

Natural polymers have been successfully used by many investigators in various approaches of floating drug delivery technology. These polymers have emerged as promising and efficacious agents having wide spectrum of desired characteristics for effective delivery of therapeutic agents. Recent advancements in better utilization of these polymers as carriers for novel stomach specific drug delivery have also been explored. These emerging drug delivery strategies at the interface of polymer chemistry and sophisticated pharmaceutical technologies will quicken the realization of full potential of this approach.It is further anticipated that design and synthesis of novel derivatizable groups of these polymers will expand the scope of new drug delivery systems in the future.

\section{References}

[1]. Singh N,Kim K.H,,Floating drug delivery systems: an approach to oral controlled drug delivery via gastric retention, J Control Release, 2000,63, 235-59.

[2]. Chawla, G, Bansal, A,A means to address regional variability in intestinal drug absorption, Pharm Tech 2003,27,50-68.

[3]. Deshpande A.A, Shah N.H, Rhodes C.T.et al,Development of a novel controlled-release system for gastric retention, Pharm Res., 1997, 14, 815-819.

[4]. Chawla G, Bansal A.,A means to address regional variability in intestinal drug absorption. Pharm Tech 2003,27,50-68.

[5]. Hirtz J,The git absorption of drugs in man: a review of current concepts and methods of investigation, J. Clin. Pharmacol.,1985, 19,77S-83S.

[6]. Hoffman A,Pharmacodynamic aspects of sustained release preparations, Adv Drug Del Rev, 1998,33,185-99.

[7]. Vasir J.K,Tambwekar K, Garg S et al, Mucoadhesive tablets as a controlled drug delivery system,International Journal of Pharmaceutics, 2003,255, 13-32. 
[8]. Rosa M, Zia H, Rhodes T et al, Dosing and testing in vitro of a bioadhesive and floating drug delivery system for oral application, Int, J. Pharm. 1994,105,65-70.

[9]. R Garg, GD Gupta, Progress in Controlled Gastroretentive Delivery Systems,Tropical Journal of Pharmaceutical Research, September 2008,7 ,1055-66.

[10] Murthy R.S.R, Biodegradable polymers, Controlled and novel drug delivery,1st Edn., CBS Publishers, New Delhi, 1997, 27-51

[11]. Beneke CE, Viljoen A.M, Hamman J.H et al, Polymeric plant-derived excipients in drug delivery, Molecules, 2009,14, 2602-20.

[12]. Bechgaard $\mathrm{H}$, Ladefoged $\mathrm{K}$, Distribution of pellets in the gastrointestinal tract. The influence on transit time exerted by the density or diameter of pellets. J. Pharm. Pharmacol. 1978, 30, 690-692.

[13]. Jain G.K, Gums and mucilages: versatile excipients for pharmaceutical formulations drug delivery systems, Asian Journal of Pharmaceutical Sciences 2009,4,309-323.

[14]. Radi Hejai,Mansoor Amiji,Chitosan based gastrointestinal Delievey Systems,J.Controlled release,2003,89,151-65.

[15]. Shahidi, F,Abuzaytoun R., Chitin, chitosan and co-products: chemistry, production, applications, and health effects. Adv. Food. Nutr. 2005,49,93-135.

[16]. He P,Davis, S.S., Illum, L., In vitro evaluation of the mucoadhesive properties of chitosan microspheres Int. J. Pharm. 1998, 166, 75-88.

[17]. Calvo P,Vila-JatoJ.L.,Alonso M.J et al,Evaluation of cationic polymer-coated nanocapsules as ocular drug carriers. Int. J. Pharm. 1997, 153, 41-50.

[18]. Bhatia M. S., Deshmukh R., Choudhari P.,Bhatia N. M.: Chemical modification of pectins, Characterization and Evaluation for Drug Delivery. Scientia Pharmaceutica (2008), 76, 775784.

[19] Kuo M.S,Dell A,Mort A.J.,Identification and location of L-glyceratel,an unusual substituent in gellan gum,Carbohydrate Res.1986,156,173-187.

[20]. Milas M,Rinaudo M,The gellan sol-gel transition,Carbohydrate Polymers ,1996,30,177-I 84.

[21]. Aspinall G.O, Bhattacharjee A.K,Biopolymers in Drug Delievery,J Chem. Soc. 1970,365369. 
[22]. Gidley M.J,Lillford P.J,Rowlands D.W.et al, Structural and solution properties of tamarind seed polysaccharide,Carbohydrate Res,1991,214,299-314.

[23]. Dea I.C.M,Morrison A.,Chemistry and interactions of seed galactomannans, Adv Carbohydrate Chem Biochem ,1975,31,242-312.

[24]. Jain A,Gupta Y,Jain S.K.et al, Perspectives of Biodegradable Natural Polysaccharides for Site-Specific Drug Delivery to the Colon,J. Pharm Pharmaceut Sci, 2007,10,86-128.

[25]. Vazquez B, Avila G, Segura D, Escalante B.et al ,Antiinflammatory activity of extracts from Aloe vera gel.,J Ethno pharmacol 1996;

[26]. Choi S, Chung M.H.,A review on the relationship between Aloe vera components and their biologic effects, Semin Integr Med ,2003,1,53-62.

[27] .Eshun K, He Q.,Aloe vera: A valuable ingredient for the food, pharmaceutical and cosmetic industries -A review,Crit Rev Food Sci Nutr,2004,44,91-96.

[28]. He Q,Changhong L, Kojo E, Tian Z.et al , Quality and safety assurance in the processing of Aloe vera gel juice,Food Control,2005,16,95-104.

[29] .Singh B, Psyllium as therapeutic and drug delivery agent. Int J Pharm 2007,334,1-14.

[30]. Rutenberg M.,Solarek D.,in Starch:Chemistry and Technology, ed. R. L. Whistler, J. Bemiller and E. Paschall. Academic Press, New York, 1984, p. 311.

[31]. Evans WC, Pharmacognosy,16th Edn,Saunders Elsevier, New York, 2009,194-218

[32].Chen J, Du GC.,Environment Friendly Material Production and Application. Beijing: Huaxue Gongye Chubanshe 2002; 46.

[33]. Sinha VR, Kumria R, Polysaccharides in colon-specific drug delivery, Int. J. Pharm., 2001, ,224,19-38.

[34].Jain A, Gupta Y, Jain SK, Perspectives of biodegradable natural polysaccharides for sitespecific drug delivery to the colon, J. Pharm. Pharmaceut.Sci.,2007,10, 86-128.

[35].Rowe RC, Sheskey P.J,Owen S.C et al , Handbook of pharmaceutical excipients, 5 th Edn.,Pharmaceutical Press, London, 2005, 315-658.

[36].Petropoulos G.A., Fenugreek: The genus Trigonella. In: Petropoulus GA, (Ed.), Botany. London: Taylor and Francis;2002.9-17. 


\section{International Journal of Pharmaceutical and Life Sciences ISSN 2305-0330 \\ Volume 2, Issue 4: October 2013}

[37].Avachat A.M, Gujar K.N, Kotwal V.B, Patil S et al ,Isolation and evaluation of fenugreek husk as granulating agent, Indian J. Pharm. Sci. 2007,69,667-679.

[38] Kokate C.K, Purohit A.P ,Gokhale S .B.,Pharmacognosy. 11th ed.; Pune; Nirali Prakashan; 1999: 498.

[39].Gangurde A. B., Malode S. S.,Bhambar R. S.,Preliminary Evaluation of Neem Gum as Tablet Binder . Indian Journal of Pharmaceutical Education \& Research 2008; 42(4):344-347.

[40] Coviello T,Alhaique F.,Dorigo A.,Matricardi P.,Grassi M. et al, Two galactomannans and scleroglucan as matrices for drug delivery: Preparation and release studies,Eur. J. Pharm. Biopharm.,2007,66,200-209.

[41]Sudhakar Y.,Kuotsu K.,Bandyopadhyay A.K et al,Buccal bioadhesive drug delivery - A promising option for orally less efficient drugs,J. Control. Release ,2006,114,15-40.

[42] Picker K.M., Matrix tablets of carrageenans:A compaction study,Drug Dev. Ind. Pharm. 1999,25,329-337. 